\title{
PERANCANGAN KARAKTER DYAH PITALOKA PADA FILM ANIMASI PERANG BUBAT
}

\section{Devvi Mutiarasani, Santi Sidhartani}

Desain Komunikasi Visual

Fakultas Bahasa dan Seni, Universitas Indraprasta PGRI

Jl. Nangka No. 58 C, Tanjung Barat, Jakarta 12530, Indonesia

devmutiara@gmail.com

\begin{abstract}
Abstrak
Perang Bubat merupakan peristiwa sejarah yang terjadi pada abad ke-14, yaitu tahun 1357 M. Kerajaan Sunda masuk kategori kerajaan besar dan tidak terkalahkan. Sampai akhirnya pecah Perang Bubat pada tahun 1357 M atau pada abad ke-14. Dyah Pitaloka adalah putri dari Raja Sunda Linggabuana. Ia mendapat lamaran dari Prabu Hayam Wuruk. Namun sebelum bertemu dengan Prabu Hayam Wuruk, Ia tewas saat perang di Bubat. Sifat yang paling menonjol dari penggambaran kisah Dyah Pitaloka ialah sifat yang berani dalam membela kehormatan orang tuanya dan negerinya. Melalui perancangan film animasi ini diharapkan para generasi muda lebih tertarik untuk mengenal Dyah Pitaloka. Pembahasan tentang karakter animasi ini menggunakan pendekatan kualitatif dengan mendesain pesan melalui elemen visual garis, bentuk, tekstur, dan warna. Melalui desain karakter animasi ini diharapkan bisa memberikan gambaran mengenai karakter dari tokoh Dyah Pitaloka dalam Peristiwa Bubat.
\end{abstract}

Kata Kunci: Perang Bubat, Dyah Pitaloka, Animasi

\begin{abstract}
Bubat War is a historical event that occurred in the 14th century, namely in 1357 AD. The kingdom of Sunda was categorized as a large and invincible kingdom. Until finally the Bubat War broke out in 1357 AD or in the 14th century. Dyah Pitaloka is the daughter of the Sundanese King Linggabuana. He got a proposal from Prabu Hayam Wuruk. But before meeting Prabu Hayam Wuruk, he died during the war in Bubat. The most prominent characteristic of the depiction of the story of Dyah Pitaloka is the nature of being brave in defending the honor of his parents and country. Through the design of this animated film it is hoped that the younger generation will be more interested in getting to know Dyah Pitaloka. The discussion of this animated character uses a qualitative approach by designing messages through visual elements of lines, shapes, textures, and colors. Through this animated character design, it is expected to be able to provide an overview of the character of the character Dyah Pitaloka in Bubat War.
\end{abstract}

Keywords: War Bubat, Dyah Pitaloka, Animation

\section{PENDAHULUAN}

Dyah Pitaloka adalah seorang putri dari Kerajaan Sunda. Dyah Pitaloka mengalami kisah kasih tidak sampai dengan raja Majapahit yaitu Prabu Hayam Wuruk. Penyebab gagalnya pernikahan Dyah Pitaloka dengan Hayam Wuruk terjadi karena sebuah kesalahpahaman. Berawal dari Prabu Hayam Wuruk yang ingin memperistri Dyah Pitaloka dan memutuskan untuk mengadakan upacara pernikahan di Majapahit, lalu Dyah Pitaloka dan rombongan pergi ke Majapahit. Sementara itu, Mahapatih Gajah Mada yang ingin mewujudkan Sumpah Palapa, 
menyatukan Nusantara memanfaatkan situasi yang tengah terjadi. Kedatangan rombongan itu dipandang sebagai tanda takluk Kerajaan Sunda dan Dyah Pitaloka dipandang sebagai upeti. Prabu Linggabuana sebagai Raja dari Kerajaan Sunda menolak tawaran Gajah Mada. Perang pun terjadi dan perang yang tidak seimbang antara pihak Gajah Mada dan rombongan Kerajaan Sunda mengakibatkan gugurnya Dyah Pitaloka dan rombongannya (Suganda, 2015:51).

Menurut Mulyani (2018:52), peristiwa Perang Bubat mendapat sambutan dan tanggapan masyarakat Sunda dan masyarakat Jawa berupa tulisan-tulisan, baik berupa kritik, artikel, dan karya sastra. Tulisan-tulisan yang berkaitan dengan Perang Bubat tersebut dapat dipandang sebagai respons masyarakat.

Dilihat dari kondisi tersebut, Perang Bubat merupakan suatu perang yang menarik untuk dibahas. Maka dari itu dibutuhkan media yang efektif untuk menyampaikan pesan dari cerita tersebut. Menurut Suryajaya (dalam Handani 2017:205), media audio visual mempunyai peran efektif untuk menjangkau komunikasi kepada masyarakat khususnya generasi muda. Salah satu media audio visual yang tepat ialah dalam bentuk film animasi karena film animasi mudah untuk dipahami, terdapat gambar bergerak dan suara, sehingga daya serap penonton akan lebih mudah dan cepat.

Salah satu aspek penting dalam perancangan film animasi adalah perancangan karakter visual. Pada film animasi yang akan dibuat, Dyah Pitaloka akan menjadi fokus utama dalam pembuatan karakter.

\section{METODE PENELITIAN}

Dalam penelitian ini pendekatan yang dilakukan adalah melalui pendekatan kualitatif. Tujuan dari penelitian kualitatif ini ialah ingin menggambarkan realitas empiris secara mendalam, rinci dan tuntas. Beberapa metode pengumpulan data pada jenis penelitian kualitatif dilakukan antara lain dengan cara studi literatur untuk mengumpulkan data, yang mana data-data tersebut didapatkan dari buku, jurnal, karya ilmiah atau data berupa tulisan lainnya. Teknik dokumentasi dilakukan dengan mengumpulkan gambar, foto, arsip, film sebagai bukti valid berupa visualisasi Dyah Pitaloka yang sudah ada sebagai referensi dalam perancangan tokoh.

Wawancara dilakukan kepada Prof. Dr. Agus Aris Munandar, M. Hum, selaku Arkeolog dan Guru Besar di Universitas Indonesia untuk mengetahui kisah Dyah Pitaloka dan penggambaran visualisasi Dyah Pitaloka.

Perancangan isi film animasi akan didasarkan pada data yang telah terkumpul. Untuk teknik perancangannya dengan mempertimbangkan teori-teori desain yang terkait dengan perancangan film animasi.

\section{HASIL DAN PEMBAHASAN \\ Film Animasi}

Animasi adalah kata yang berasal dari Latin yaitu "anima" yang berarti membuat gambar seolah-olah terlihat dapat bergerak, sedangkan pengertian film animasi adalah sebuah film yang berasal dari rangkaian gambar-gambar yang diolah sehingga terlihat seperti bergerak dan memiliki cerita. Animasi dibagi menjadi dua bagian, di antaranya adalah animasi 2D (dua dimensi) dan animasi 3D (tiga dimensi) (Gunawan, 2013: 26). Dapat disimpulkan bahwa animasi adalah usaha untuk menampilkan gambar secara berurutan dan bergerak cepat sehingga membuat gambar terlihat hidup.

Berdasarkan uraian di atas, maka animasi merupakan teknik pembuatan karya visual yang dapat bergerak dengan serangkaian gambar, sehingga gambar menjadi alur jalan cerita yang dapat menyampaikan pesan atau informasi.

Animasi yang akan digunakan dalam perancangan ini adalah animasi dua dimensi. Gunawan, (2013:27) memaparkan bahwa Animasi 2D adalah teknik pembuatan animasi dengan menggunakan gambar bersumbu (axis) $\mathrm{X}$ dan $\mathrm{Y}$. Animasi ini lebih dikenal dengan animasi manual yang prosesnya dimulai dengan menggambar di atas selembar kertas, kemudian dipindai dan baru dipindahkan ke dalam komputer untuk diubah menjadi file digital. 


\section{Karakter Visual}

Menurut White (dalam Sumarli 2018:164), dalam sebuah animasi atau komik, selain cerita, desain karakter sangatlah penting. Desain karakter bisa menarik minat penonton dan desain karakter yang baik mampu memberikan impact kepada para penonton. Contohnya. jika menggunakan bentuk gaya garis yang melengkung akan membuat karakter terkesan manis dan gaya garis yang kotak akan membuat karakter terlihat agresif.

Penelitian tentang penciptaan karakter visual juga telah dilakukan oleh Pratama, dkk (2018:88), di mana disampaikan bahwa desain karakter dapat dibangun melalui elemen desain garis, bentuk, tekstur, dan warna. Elemen garis dan bentuk dapat menghadirkan kepribadian, emosi, ekspresi, dan mewakili identitas seperti gender, kelas sosial, dan nilai-nilai budaya melalui ilustrasi pakaiannya. Garis bertanggung jawab tidak hanya untuk mendeskripsikan bentuk dalam desain karakter, tetapi juga memperhitungkan ketebalan garis, orientasi garis, posisi garis dan jenis garis. Sedangkan elemen visual dari bentuk juga dapat digunakan untuk menentukan elemen internal karakter. Bentuk tidak hanya dapat menghasilkan karakter penampilan yang khas, tetapi juga konotasi tipe karakter dan kepribadian, seperti pengembangan lingkaran, segitiga dan kotak.

Selanjutnya, menurut Irawan (dalam Pratama, dkk, 2018:88), elemen desain tekstur adalah keadaan fisik dari suatu permukaan material yang dapat dirasakan dengan indera peraba atau bisa dirasakan melalui indra penglihatan seperti tekstur lihat. Tekstur dapat dilihat sebagai tekstur pseudo karena sifat keberadaannya yang merupakan hasil gambar 2D.

Sedangkan menurut Danesi (dalam Pratama, dkk, 2018:88), elemen desain warna adalah efek dari tanda yang dapat digunakan untuk mewakili apa saja yang dinilai sesuai. Secara semiotik, warna tanda visual digunakan untuk tujuan konotatif. Ada makna sensoris dan emosional yang melekat pada warna. Dengan kata lain, melalui warna, seseorang dapat merasakan warna lebih dari sebuah fenomena yang melibatkan persepsi visual saja. Khususnya dalam budaya masyarakat, warna memainkan fungsi yang sangat penting di bidang simbolisme. Elemen warna dapat menjadi signifikansi penting untuk membawa pesan dan makna.

\section{Tokoh Dyah Pitaloka dalam Perang Bubat}

Dyah Pitaloka adalah putri dari Raja Sunda Linggabuana. Di dalam Kidung Sundayana diceritakan bahwa raja Majapahit Prabu Hayam Wuruk sedang mencari pendamping hidup. Mendengar kabar akan kecantikan putri kerajaan Sunda, Hayam Wuruk mengutus seorang petinggi Majapahit dan seorang pelukis Majapahit untuk pergi melukis putri kerajaan Sunda yaitu Dyah Pitaloka. Setelah melihat lukisan putri Sunda, Hayam Wuruk langsung jatuh hati dan mengutus Patih Madhu menghadap raja Sunda, membawa sepucuk surat untuk meminang sang putri (Pratama, 2015:7). Dyah Pitaloka tidak banyak berkomentar pada saat itu menuruti keinginan ayahnya untuk dijodohkan dengan Prabu Hayam Wuruk yang merupakan raja kerajaan Majapahit dengan maksud untuk mempererat tali kekerabatan. Lamaran diterima baik oleh pihak Sunda, dan berangkatlah rombongan Sunda ke Majapahit. Lalu rombongan Sunda datang ke Majapahit untuk mengadakan pernikahan. Saat itu terjadi kesalahpahaman antara Kerajaan Sunda dan Kerajaan Majapahit. Kerajaan Sunda datang ke Majapahit untuk menikahkan Dyah Pitaloka dengan Prabu Hayam Wuruk, tetapi pihak Majapahit keberatan dan menginginkan Dyah Pitaloka untuk dijadikan upeti atau persembahan, Kerajaan Sunda tidak setuju. Sebagai Ksatria Sunda, semua rombongan Sunda memilih untuk perang daripada takluk kepada Majapahit, maka terjadilah perang. Akhirnya semua rombongan Sunda yang ada di sana gugur, termasuk Ayahanda Dyah Pitaloka. Sebelum Dyah Pitaloka bertemu dengan Prabu Hayam Wuruk, ia melakukan bunuh diri demi membela negeri Sunda (Munandar 2009,86).

Seperti yang diceritakan di atas bahwa Dyah Pitaloka berserta rombongan Sunda datang ke Majapahit untuk menikah dengan Hayam Wuruk, tetapi dipandang sebagai upeti oleh Mahapatih Gajah Mada, Dyah Pitaloka mempertahankan harga diri agar menjaga kehormatan negerinya. Hal ini menyatakan suatu sikap ingin membela tanah air atau negara dari penguasaan dan penjajahan bangsa asing yang merupakan arti dari nasionalisme (Oktaviani, 2013). 
Menurut Prof. Dr. Agus Aris Munandar, M. Hum, Dyah Pitaloka merupakan putri yang sangat cantik, anggun dan menjaga wibawanya. Ia memiliki sifatnya yang baik, cerdas, berbakti kepada orang tua, dan juga berani. Sifat yang paling menonjol dari penggambaran kisah Dyah Pitaloka ialah sifat yang berani dalam membela kehormatan negeri dan orang tuanya.

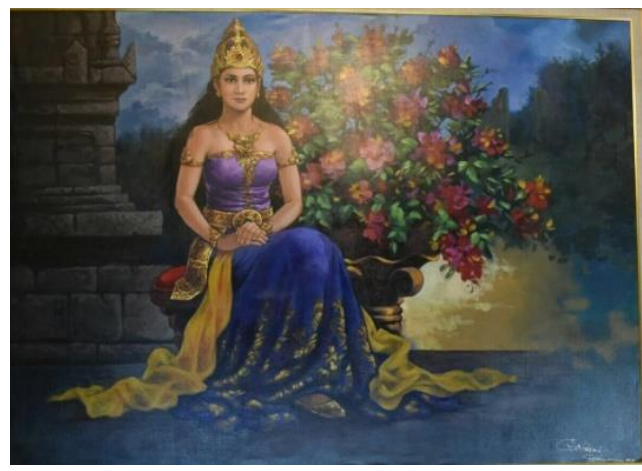

Gambar 1 Lukisan Dyah Pitaloka

Sumber: Dokumen Pribadi Dedy Mulyadi Bupati Purwakarta ke-8.

Prof. Dr. Agus Aris Munandar, M. Hum, menambahkan bahwa Dyah Pitaloka memiliki rambut yang tergerai hingga pinggang. Busana yang Dyah Pitaloka gunakan ialah kain selendang panjang, baju sutera tepiannya dihiasi dengan benang emas. Di bagian tubuh menggunakan gelang ganda pada lengannya, kalung medalion melebar, kelat bahu atau gelang yang dipakai di pangkal lengan kanan dan kiri, hiasan telinga, cincin, dan hiasan kepala bertatahkan mutiara di dahinya.

\section{Perancangan Karakter Visual Tokoh Dyah Pitaloka}

Pada visualisasi karakter, penulis pertama-tama membuat sketsa yang sesuai dengan karakteristik tokoh. Visualisasi karakter tokoh yang terdapat dalam kisah Perang Bubat ini difokuskan hanya pada Karakter Dyah Pitaloka yang dibuat dalam bentuk 2D (dua dimensi). Perancangan karakter pada tokoh animasi ini akan tetap mengadaptasi dari lukisan Dyah Pitaloka yang kemudian dibuat dengan gaya kartun, menggambarkan sebagai sosok perempuan yang cantik, dan anggun seperti putri kerajaan pada umumnya, memiliki rambut panjang, menggunakan selendang, dan memakai aksesoris seperti putri kerajaan.

Target audiens lebih difokuskan bagi remaja dengan usia 16-18 tahun, yang senang dengan film animasi dengan gaya peperangan. Film animasi dapat membuat proses pengenalan tokoh sejarah menjadi lebih efektif dan efisien karena dapat mempermudah untuk menyampaikan informasi.

Dalam perancangan karakter ini, penulis menggunakan struktur garis, bentuk, tekstur, dan warna. Beberapa elemen-elemen visual dalam membentuk perancangan karakter Dyah Pitaloka sebagai berikut:

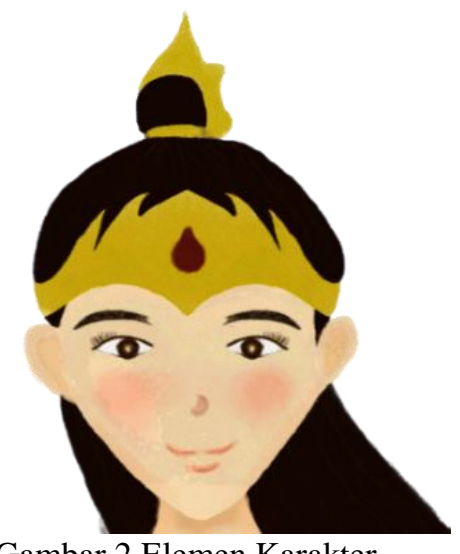

Gambar 2 Elemen Karakter.

Sumber: Dokumen Pribadi 
1. Karakter garis melengkung pada wajah menunjukkan karakter yang kuat dan penuh semangat.

2. Garis lengkung beraturan pada mahkota menunjukkan karakter kejelasan dan teratur.

3. Garis tidak rata pada rambut menunjukkan sikap yang lembut.

4. Tekstur semu pada wajah di pipi memberikan kesan indah dan menarik.

5. Bentuk wajah seperti segitiga yang lancip di bawah memiliki karakter yang baik hati.

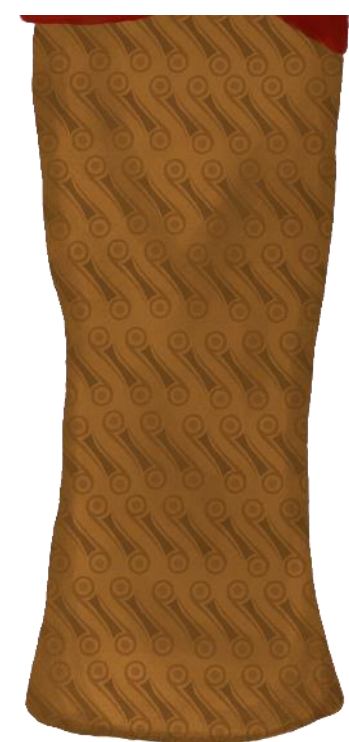

Gambar 3 Elemen karakter Sumber: Dokumen Pribadi

1. Garis lengkung pada kain menunjukkan karakter yang tidak kaku.

2. Tekstur kain yang halus dan bermotif batik yang digunakan pada masa sunda kuno menunjukkan karakter kaum bangsawan.

3. Tekstur semu pada kain memiliki unsur gelap terang agar memiliki dimensi.

4. Kain berwarna cokelat tradisional menunjukkan bangsawan sunda.

5. Bentuk dasar persegi panjang pada kain yang telah mengalami perubahan memiliki karakter yang percaya diri.

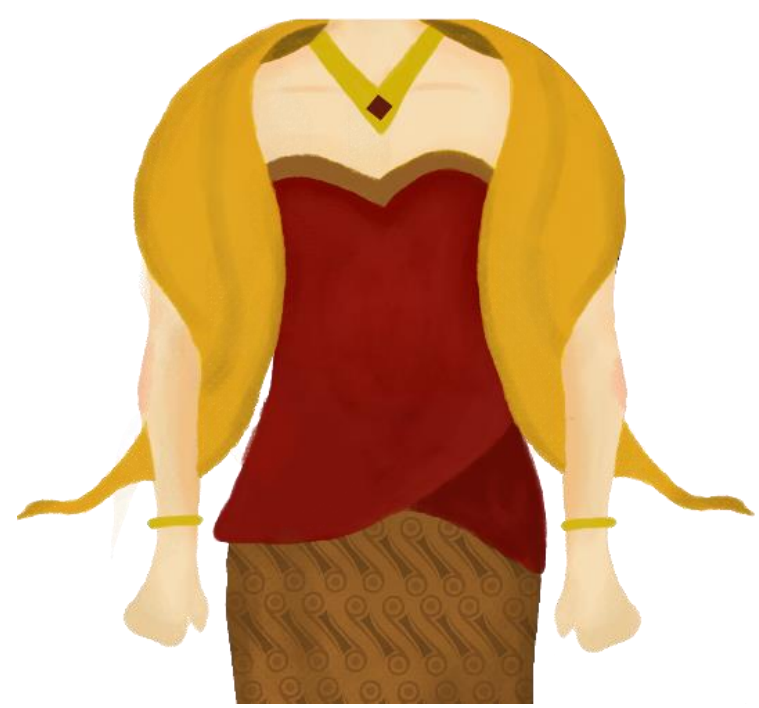

Gambar 4 Elemen karakter.

Sumber: Dokumen Pribadi 
1. Garis lengkungan pada selendang menunjukkan karakter lembut dan tidak kaku.

2. Garis lengkung pada kemban yang membentuk lekuk tubuh menunjukkan karakter feminin, keanggunan, kewibawaan.

3. Garis lurus di dada menunjukkan ketenangan dan ketegasan.

4. Tekstur selendang seperti sutra di mana kain yang digunakan untuk para bangsawan yang bersifat halus dan lembut.

5. Warna merah pada kemban agar terlihat menarik perhatian.

6. Warna keemasan pada aksesoris seperti gelang, kalung, mahkota menunjukkan kemuliaan.

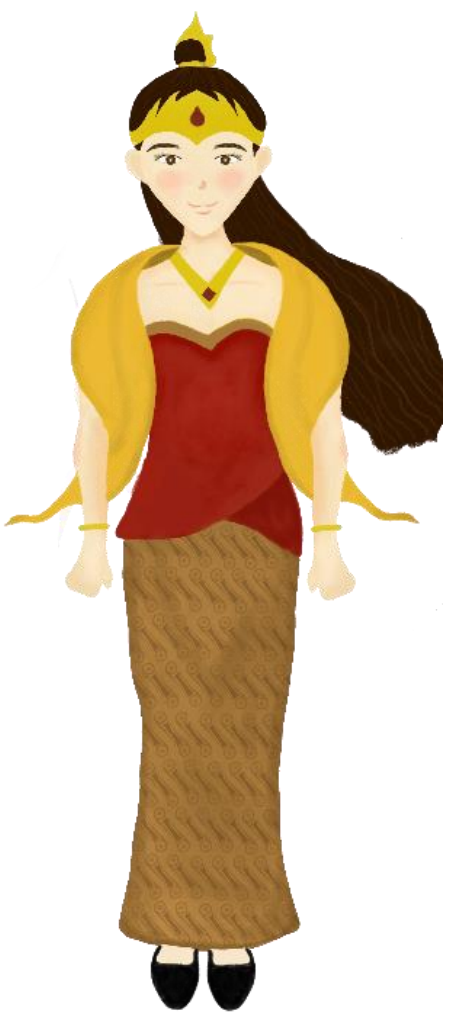

Gambar 5 Karakter Visual Dyah Pitaloka.

Sumber: Dokumen Pribadi

Dari hasil perancangan elemen karakter di atas terciptalah karakter visual Dyah Pitaloka. Kesan yang didapat dari keseluruhan bahwa bentuk tubuh menunjukkan keseimbangan, kekuatan, sikap positif. Garis-garis pada wajah dan tubuh menunjukkan kejelasan, kesan tinggi, gerakan, energi, dan keseriusan. Warna merah dan cokelat pada pakaian merupakan warna tradisional. Tekstur yang digunakan pada kain menunjukkan bentuk motif batik.

\section{SIMPULAN}

Simpulan yang dapat diambil dari penelitian ini adalah setiap perancangan karakter untuk animasi harus memiliki data-data yang valid untuk mengaplikasikannya ke dalam karakter ataupun cerita. Dari hasil penelitian dan data visual yang ada terciptalah karakter tokoh Dyah Pitaloka yang dirancang menggunakan elemen-elemen visual seperti struktur garis, bentuk, tekstur dan warna. Sehingga perancangan karakter Dyah Pitaloka akan menjadi tokoh utama dalam film animasi Perang Bubat.

Peneliti memilih tokoh Dyah Pitaloka untuk dijadikan film animasi karena sifat-sifat baik Dyah Pitaloka yang dapat dijadikan teladan bagi anak-anak, di antaranya ialah sifatnya yang baik, cerdas, berbakti kepada orang tua, dan juga berani. Sifat yang paling menonjol dari penggambaran kisah Dyah Pitaloka ialah sifat yang berani dalam membela kehormatan orang tuanya. Melalui perancangan film animasi ini diharapkan para generasi muda lebih tertarik untuk mengenal Dyah 
Pitaloka. Pembahasan tentang karakter animasi ini menggunakan pendekatan kualitatif dengan mendesain pesan melalui elemen visual garis, bentuk, tekstur, dan warna. Melalui desain karakter animasi ini diharapkan dapat memberikan gambaran mengenai karakter dari tokoh Dyah Pitaloka dalam Peristiwa Bubat.

\section{DAFTAR PUSTAKA}

Gunawan, B. B. (2013). Nganimasi Bersama Mas Be!. Jakarta: PT Elex Media Komputindo.

Handani, S. W., \& Nafianti, D. R. (2017). Perancangan film pendek animasi 3 dimensi legenda Desa Penyarang. JURNAL INFOTEL, 9(2), 204-211.

Munandar, A A. (2009). Gajah Mada: Kuasa, cita-cita, dan Prahara. Bogor: Akademia.

Oktaviani, Y. O. (2013). Pengaruh Film Tanah Air Beta Terhadap Sikap Nasionalisme Siswa. (Skripsi). Universitas Muhammadiyah Surakarta: Surakarta.

Pratama, D., Gunarti, W., \& Akbar, T. (2017). Understanding visual novel as artwork of visual communication design. Mudra Jurnal Seni Budaya, 32(3), 292-298.

Pratama, D., Wardani, W. G. W., \& Akbar, T. (2018). Designing Visual Novel Characters of Gajah Mada and Tribhuwana Tunggadewi As Representation of History Figures. Humanus, 17(1), 84-96.

Pratama, Y. A. (2015). Perancangan Komik Perang Bubat Berdasarkan Naskah Kidung Sundayana. Skripsi. Universitas Komputer Indonesia: Bandung.

Suganda. H. (2015). Kerajaan Galuh: Legenda, takhta, dan wanita. Bandung: Kiblat Buku Utama.

Sumarli, C. O., \& Kurnianto, A. (2018). Developing karakter animasi berbasis kudapan khas Tionghoa. Jurnal Desain, 5(03), 162-173.

Supriatin, Y. M. (2018). Perang Bubat, Representasi sejarah abad ke-14 dan resepsi sastranya. Patanjala:Jurnal Penelitian Sejarah dan Budaya, 10(1), 51-56. 